\title{
Preparation of U-Zr-Mn, a Surrogate Alloy for Recycling Fast Reactor Fuel
}

\author{
Jong-Hwan Kim, Ki-Hwan Kim, and Chan-Bock Lee \\ Next Generation Fuel Division, Korea Atomic Energy Research Institute, Daejeon 305-353, Republic of Korea \\ Correspondence should be addressed to Jong-Hwan Kim; jhk9@kaeri.re.kr
}

Received 27 May 2015; Revised 26 August 2015; Accepted 8 September 2015

Academic Editor: Randhir Singh

Copyright (C) 2015 Jong-Hwan Kim et al. This is an open access article distributed under the Creative Commons Attribution License, which permits unrestricted use, distribution, and reproduction in any medium, provided the original work is properly cited.

\begin{abstract}
Metallic fuel slugs of U-10Zr-5Mn (wt\%), a surrogate alloy for the U-TRU-Zr (TRU: a transuranic element) alloys proposed for sodium-cooled fast reactors, were prepared by injection casting in a laboratory-scale furnace, and their characteristics were evaluated. As-cast U-Zr-Mn fuel rods were generally sound, without cracks or thin sections. Approximately $68 \%$ of the original Mn content was lost under dynamic vacuum and the resulting slug was denser than those prepared under Ar pressure. The concentration of volatile Mn was as per the target composition along the entire length of the rods prepared under 400 and 600 Torr. Impurities, namely, oxygen, carbon, silicon, and nitrogen, totaled less than 2,000 ppm, satisfying fuel criteria.
\end{abstract}

\section{Introduction}

A metallic fuel is a promising candidate to power sodiumcooled fast reactors (SFRs). Compared with other fuel forms, the higher densities of fissile and fertile materials in metallic fuels offer superior reactor core performance, hence affording increased breeding ratio and reducing the fissile inventory [15].

However, the low melting temperature of metallic fuels such as pure $\mathrm{U}, \mathrm{Pu}$, and $\mathrm{U}-\mathrm{Pu}$ alloys makes them unsuitable for high-temperature applications because of the dangers associated with molten elements penetrating the cladding. The addition of certain high melting temperature elements such as $\mathrm{Cr}, \mathrm{Mo}, \mathrm{Ti}$, and $\mathrm{Zr}$ has therefore been investigated to boost the liquidus temperature and enhance the thermal and mechanical stability of the alloy system.

The excellent corrosion resistance and mechanical stability during the cycling of U-Zr-based alloys make them promising nuclear fuels. Moreover, $\mathrm{Zr}$ metal has a low thermal-neutron cross section and is unique in suppressing interdiffusion between the nuclear fuel and stainless-steel cladding. These favorable properties have led to the development of U-Zr fuel systems for SFRs.

Over several decades, various methods have been developed to fabricate metallic fuel, such as rolling, swaging, wire drawing, and coextrusion; however, these processes are limited by the additional steps that are required and by complex setups, making them unsuitable for remote use [2, $6,7]$. For SFR applications, metallic fuel needs to be massproduced remotely and inexpensively, while minimizing the amount of radioactive wastes. Casting is one of the oldest manufacturing processes and is used to produce shapes that are not readily machined. By carefully choosing the mold and the filling method, injection casting can be used advantageously to prepare small-diameter castings with a high length/diameter ratio and a randomly oriented grain structure.

In injection casting, the pressure difference between the interior of the mold and the furnace is exploited to drive the molten metal up into a quartz tube, either under a dynamic vacuum or a low-pressure atmosphere. A large number of input parameters have to be defined for this process, relating to the casting machine, injection, mold, and cast metal. Among these, the melt temperature, injection pressure, mold temperature, and pressure holding time are crucial, because small deviations from the optimal values can substantially degrade the quality of the product.

In the present work, a laboratory-scale induction furnace was designed and constructed to study injection casting variables and handling techniques. Firstly, a surrogate copper 


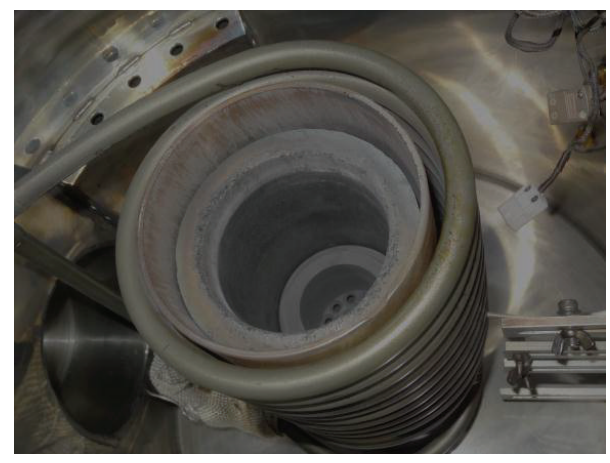

FIgURE 1: Induction copper coil used for heating the raw materials.

slug, whose melting temperature is similar to that of uranium, was prepared to evaluate the effect of injection casting variables on the fuel slug. Then, $\mathrm{U}-10 \mathrm{Zr}-5 \mathrm{Mn}$ slugs (wt $\%$ ), surrogates for the U-TRU-Zr slugs (TRU: a transuranic element) advanced for SFRs, were produced and their characteristics were evaluated.

\section{Experimental}

Figure 1 shows the induction copper coil used in this study. In keeping with the scale of the equipment, casting was conducted in a small furnace with a capacity of $\sim 0.5 \mathrm{~kg} \mathrm{U}-\mathrm{Zr}$ alloy per batch operation. The main components are a melting furnace, a vacuum pumping system, and a pressuring system. The intention here is to prove the practicality of injection casting as a means of producing fuel slugs and to furnish the necessary design information for hot-cell applications. Components such as the crucible, crucible cover, graphite insulation, and water-cooled copper induction coil are contained within the furnace.

The chamber has a double-shell structure for water cooling and the chamber cover is designed to rotate to facilitate the separation of the mold assembly before and after casting. The quartz mold is preheated using a cartridge heater and insulated with ceramic wool. Pressurized inert gas was used to force molten metal, stored in the accumulator tank adjacent to the casting furnace, into quartz molds. For this study, the feedstock materials were weighed in proportion to the alloy composition and charged into a melting crucible. The crucible was heated at $100^{\circ} \mathrm{C} / \mathrm{min}$ and elevated to the target temperature by induction copper coil.

Before injecting the melt, the heating power was reduced from $100 \%$ to $0 \%$ to maximize the electromagnetic force and homogenize the alloy via electromagnetic stirring. Once the quartz mold and alloy melt had reached the target temperature, the former was immersed in the latter and the chamber was filled with pressurized gas to inject the molten alloy into the mold. After injection casting, the fuel slug was extracted from the mold in a glove box.

Fuel slugs were cut into slices of suitable thickness using a slow-speed SiC abrasive cut-off wheel and the density at each location was measured using Archimedes' principle. The microstructures and compositions were analyzed using scanning electron microscope (SEM) with energy-dispersive $\mathrm{X}$-ray spectroscope (EDS). Casting yields and fuel losses were evaluated by measuring the material balance before and after casting. The chemical composition of the fuel slugs and the presence of impurities were also assessed by inductively coupled plasma atomic emission spectrometry (ICP-AES).

\section{Results and Discussion}

Assuming a homogeneous liquid at constant temperature, the height of the liquid in the mold can be expressed in terms of the applied pressure as follows:

$$
h=\frac{1}{\rho} \times \frac{p}{g},
$$

where $h$ is height of the liquid, $p$ is the fluid pressure, $g$ is the gravitational constant, and $\rho$ is the density of the liquid. However, for dynamic systems such as metallic fuel melts, many factors neglected in this equation hinder the rise of the melt, namely, the wettability, the cooling rate, temperature and density variations, and other hydraulic effects. These hindering effects can be circumvented by superheating the melt, preheating the mold, and increasing the pressure difference between the mold's interior and the furnace. However, because these factors affect one another, they should be optimized carefully.

Before using radioactive uranium, a copper slug was cast to study the interplay of these variables and optimize the handling of the apparatus. Copper has a melting temperature similar to that of uranium but does not carry a radiation risk. Table 1 lists the furnace pressures and other experimental parameters used to cast the copper slug (tests $a-d$ ). The holding time is the delay between the submersion of the mold tip and the pressurization of the furnace. The immersion time is the delay between the submersion and retraction of the mold tip.

Test $a$ was performed under dynamic vacuum conditions, at an injection pressure of $\sim 0.8 \mathrm{kgf} / \mathrm{cm}^{2}$, and with no electromagnetic induction while the mold was immersed. As shown in Figure 2(a), the $\mathrm{Cu}$ slug obtained was attached to the heel at the bottom of the mold as a result of the low casting temperature or relatively long immersion time. Nonetheless, the slug filled and was cast to the full length of the mold, with no thin sections observed.

In order to prevent the slug from solidifying too rapidly and becoming attached to the heel, in test $b$, induction was maintained until the mold was removed from the melt-the conditions being otherwise the same as those used for test a. Figure 2(b) shows that the resulting $\mathrm{Cu}$ slug was cast to the full length of the mold but not attached to the heel. The surface is however coarser in the lower region (left side of the photograph), where the temperature was highest during casting, than in the middle and upper regions of the slug.

Temperature is known to be the most important casting variable because it governs both the fluidity of the melt during mold filling and the surface state of the slug via its interactions with the hot mold. Shrinkage defects appear more readily in high-temperature melts; the melt temperature 
TABLE 1: Experimental parameters for injection casting of $\mathrm{Cu}$ and $\mathrm{U}-10 \mathrm{Zr}-5 \mathrm{Mn}$ fuel slugs.

\begin{tabular}{lccccccc}
\hline & Test $a$ & Test $b$ & Test $c$ & Test $d$ & Test $e$ & Test $f$ & Test $g$ \\
\hline $\begin{array}{l}\text { Charge alloy } \\
\text { composition }(\mathrm{wt} \%)\end{array}$ & $\mathrm{Cu}$ & $\mathrm{Cu}$ & $\mathrm{Cu}$ & $\mathrm{Cu}$ & $\mathrm{U}-10 \mathrm{Zr}-5 \mathrm{Mn}$ & $\mathrm{U}-10 \mathrm{Zr}-5 \mathrm{Mn}$ & $\mathrm{U}-10 \mathrm{Zr}-5 \mathrm{Mn}$ \\
\hline $\begin{array}{l}\text { Casting temperature } \\
\left({ }^{\circ} \mathrm{C}\right)\end{array}$ & 1160 & 1160 & 1120 & 1120 & 1530 & 1450 & 1450 \\
\hline $\begin{array}{l}\text { Injection pressure } \\
\left(\mathrm{kgf} / \mathrm{cm}^{2}\right)\end{array}$ & 0.8 & 0.8 & 0.8 & 0.8 & 2.5 & 3.4 & 3.4 \\
\hline $\begin{array}{l}\text { Chamber atmosphere } \\
\text { before injection }\end{array}$ & $\begin{array}{c}\text { Dynamic } \\
\text { vacuum } \\
\text { condition }\end{array}$ & $\begin{array}{c}\text { Dynamic } \\
\text { vacuum } \\
\text { condition }\end{array}$ & $\begin{array}{c}\text { Dynamic } \\
\text { vacuum } \\
\text { condition }\end{array}$ & $\begin{array}{c}\text { Dynamic } \\
\text { vacuum } \\
\text { condition }\end{array}$ & $\begin{array}{c}\text { Dynamic } \\
\text { vacuum } \\
\text { condition }\end{array}$ & $\begin{array}{c}\text { Ar } \\
(400 \text { Torr })\end{array}$ & $\begin{array}{c}\text { Ar } \\
(600 \text { Torr })\end{array}$ \\
\hline Holding time $(\mathrm{sec})$ & 2 & 2 & 2 & 2 & 4 & 5 & 2 \\
\hline Emerging time $(\mathrm{sec})$. & 18 & 18 & 18 & 10 & 5 & 2 \\
\hline
\end{tabular}

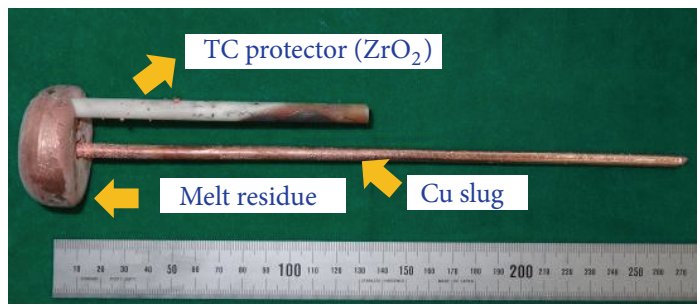

(a)

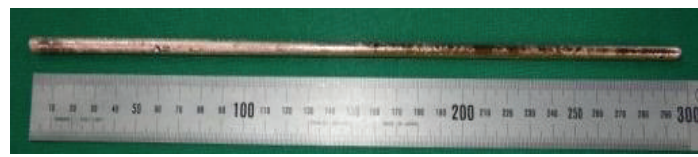

(b)

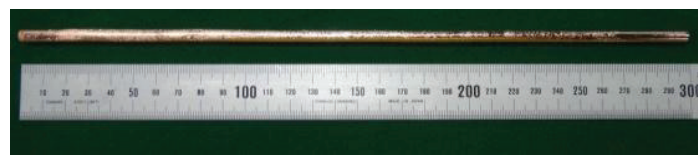

(c)

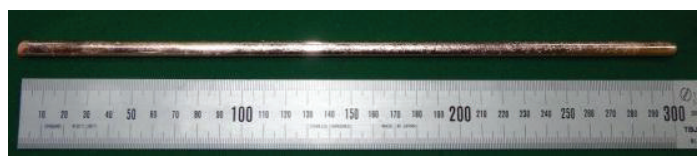

(d)

FIGURE 2: Photographs of surrogate copper slugs prepared in (a) test $a$, (b) test $b$, (c) test $c$, and (d) test $d$.

should therefore be kept as low as possible to improve the quality of the casts, while ensuring nonetheless that the melt fills the mold adequately. For test $c$, the casting temperature was lowered from 1160 to $1120^{\circ} \mathrm{C}$ and indeed Figure 2(c) shows that the surface state of the $\mathrm{Cu}$ slug is better than that of the slugs obtained in test $a$ or $b$.

Figure 2(d) shows the Cu slug fabricated under the same conditions as those used for test $c$, but with the delay between the submersion of the mold tip in the melt and its retraction reduced from 18 to $10 \mathrm{~s}$ (test $d$ ). The objective was to reduce the heating time in the melt and thereby reduce the thermal stress on the lower part of the slug. The fuel slug did not drip back into the melt and its surface condition is visibly improved (Figure 2(d)).

Based on these preliminary tests with copper, U-Zr$\mathrm{Mn}$, a surrogate alloy for U-TRU-Zr, was injection cast. UTRU ingots, the raw nuclear fuel for SFRs, are converted through pyroprocessing from spent fuel generated in nuclear power plants and contain volatile minor actinide such as Am. Volatile elements are difficult to melt and cast because they tend to vaporize and are often poorly incorporated in the product. A simple solution to this problem is to enrich the casting charge and accept the loss, as in conventional casting; however, this approach is not suitable for radioactive materials, in particular, those containing minor actinides which may transmute into short-lived or nonactive elements in the nuclear reactor.

The equilibrium vapor pressure of $\mathrm{Am}$ at $1465^{\circ} \mathrm{C}$ is about 3.3 Torr, and over the range of melting temperatures, the vapor pressure of Am is nearly three orders of magnitude higher than that of $\mathrm{Pu}$. The vapor pressures of $\mathrm{U}$ and $\mathrm{Zr}$ are known to be 3 and 4.5 orders of magnitude less than that of $\mathrm{Pu}$, respectively [8-13]. This implies that $\mathrm{Am}$ is the element most likely to be lost as vapor during the casting process. According to [13-15], Mn has a vapor pressure similar to that of Am in the temperature range of $1200-1600^{\circ} \mathrm{C}$ (Figure 3). In addition, the U-rich end of the U-Mn phase diagram exhibits no liquid miscibility [16]. Thus, Fielding investigated the use of a U-Mn-Zr alloy system to simulate the loss of Am during the melting process [17].

The furnace temperatures and other experimental parameters used to cast the U-Zr-Mn slugs are listed in Table 1 (tests $e-g$ ). The volatility of Mn was estimated under dynamic vacuum conditions in test $e$ and under pressures of 400 and 600 Torr in tests $f$ and $g$, respectively. The casting temperature is an important variable in the casting of fuel slug, and it is affected by many factors such as casting shape (length, diameter, volume, and area), batch size, mold filling time, cooling conditions, and casting method. In this study, casting temperature is referred to [18], where U-Zr-Mn alloy slug was fabricated soundly.

Figure 4(a) shows an as-cast U-Zr-Mn slug prepared under dynamic vacuum conditions at an injection pressure of $2.5 \mathrm{kgf} / \mathrm{cm}^{2}$ (test $e$ ). The slug fills the full length of the 


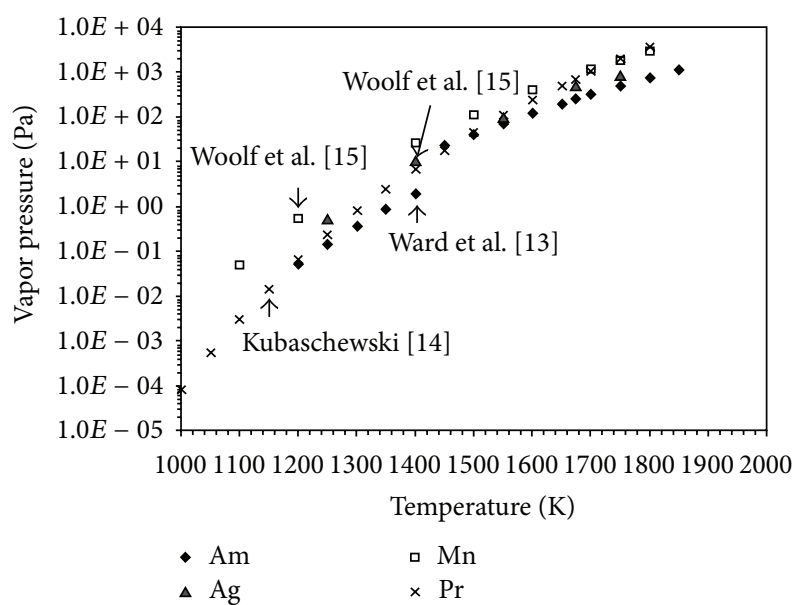

FIGURE 3: Vapor pressure of americium, manganese, silver, and praseodymium as a function of temperature [7, 13-15].

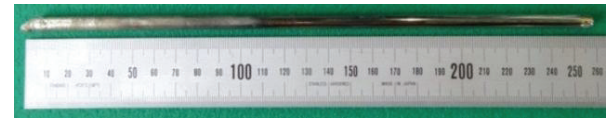

(a)

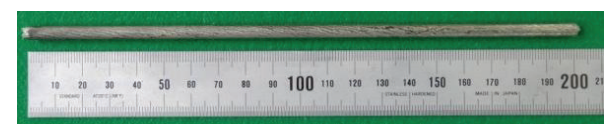

(b)

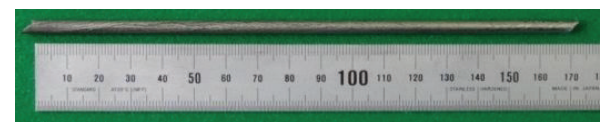

(c)

Figure 4: Photographs of $\mathrm{U}-10 \mathrm{Zr}-5 \mathrm{Mn}$ slugs prepared in (a) test $e$, (b) test $f$, and (c) test $g$.

mold and is generally sound with no cracks or thin sections visible. As for the $\mathrm{Cu}$ slug, the bottom surface is rougher, where the quartz mold was immersed in the melt (left side of the photograph), and some reaction layers are observed.

For tests $f$ and $g$, the casting temperature was lowered from 1530 to $1450^{\circ} \mathrm{C}$, to reduce the risk of $\mathrm{Mn}$ vaporization and improve the surface state of the resulting slug. As shown in Figures 4(b) and 4(c), the slug shortens as the atmosphere pressure is increased, reflecting the corresponding increase in the repulsive pressure during mold filling.

Figure 5 shows the density of the U-10Zr-Mn slugs as measured from samples taken from the lower, middle, and upper portions of each slug. The average densities are 15.7, 15.3 , and $14.8 \mathrm{~g} / \mathrm{cm}^{3}$ for the fuel slugs prepared in tests $e, f$, and $g$, respectively. The low standard deviations associated with each value $\left( \pm 0.2 \mathrm{~g} / \mathrm{cm}^{3}\right)$ show that the inductive forces during melting and alloying were sufficient to mix the melt homogeneously. Figure 5 shows furthermore that the U-ZrMn slug prepared under dynamic vacuum (test $e$ ) is denser than the one prepared under pressure. This is the result of Mn

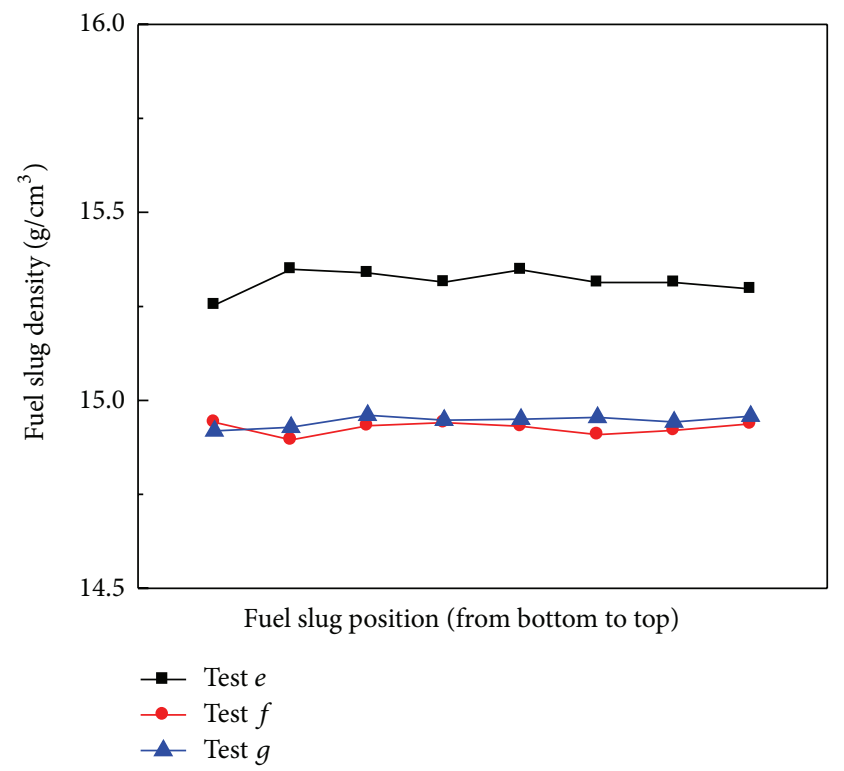

FIGURE 5: Distributions of fuel slug density according to the position of fuel slug.

vaporization. Indeed, as $\mathrm{Mn}$ is vaporized more readily than the other elements, the concentrations of $\mathrm{U}$ and $\mathrm{Zr}$ and the density of the alloy increase notably because the atomic mass of $\mathrm{U}$ is more than twice that of $\mathrm{Mn}$. However, vaporization is inhibited under Ar pressure (tests $f$ and $g$ ), resulting in slugs with a higher Mn content and lower density. The fact that the density of the slugs prepared under Ar is homogeneous along their length implies that pressures up to 400 Torr do not have a significant effect on the vaporization of $\mathrm{Mn}$. This effect is quantified below in terms of the chemical composition of the casts.

The chemical compositions of the surrogate fuel slugs were obtained by ICP-AES. Table 2 shows the $\mathrm{Mn}$ and $\mathrm{Si}$ concentrations measured in the lower, middle, and upper portions of each slug. Under dynamic vacuum conditions (test c), approximately $68 \%$ of the original Mn content is lost by vaporization, indicating that dynamic vacuums are unsuitable for the fabrication of fuel slugs containing volatile radioactive constituents such as Am. Under 400 and 600 Torr Ar, however, the Mn content is as per the target composition along the entire length of the slugs, indicating that the volatile element was retained throughout the melting and alloying processes. The average Mn content of these slugs is $~ 5.1 \mathrm{wt} \%$.

The impurity (i.e., oxygen, carbon, silicon, and nitrogen) content of the slugs is less than 2,000 ppm and thereby satisfies the tentative criteria defined for Experimental Breeder Reactor II fuel. Silicon is found in a higher concentration toward the bottom of the slug, the region in contact with melt, because of reactions with the melt during injection.

Figure 6 shows the U, Zr, and Mn concentrations measured in the lower, middle, and upper portions of the slugs. The fuel slugs prepared at 400 and 600 Torr have $\mathrm{Zn}$ contents in the target (11.0-9.0 $\mathrm{wt} \% \mathrm{Zn}$ ) range; however, the fuel slug prepared under dynamic vacuum is richer in $\mathrm{U}$ and $\mathrm{Zr}$, as 
TABLE 2: Concentrations of $\mathrm{Mn}$ and $\mathrm{Si}$ according to position of $\mathrm{U}-10 \mathrm{Zr}-5 \mathrm{Mn}$ fuel slugs prepared by injection casting.

\begin{tabular}{|c|c|c|c|c|c|c|}
\hline \multirow{2}{*}{ Fuel slug location } & \multicolumn{2}{|c|}{ Test $e$} & \multicolumn{2}{|c|}{ Test $f$} & \multicolumn{2}{|c|}{ Test $g$} \\
\hline & $\mathrm{Mn}(\mathrm{wt} \%)$ & $\mathrm{Si}(w \mathrm{t} \%)$ & $\mathrm{Mn}(\mathrm{wt} \%)$ & $\mathrm{Si}(\mathrm{wt} \%)$ & $\mathrm{Mn}(\mathrm{wt} \%)$ & $\mathrm{Si}(\mathrm{wt} \%)$ \\
\hline \multicolumn{7}{|l|}{ Lower } \\
\hline 1 & 1.51 & 0.09 & 5.19 & 0.03 & 5.01 & 0.06 \\
\hline 2 & 1.52 & 0.04 & 5.03 & 0.02 & 5.26 & 0.02 \\
\hline \multicolumn{7}{|l|}{ Middle } \\
\hline 1 & 1.49 & 0.02 & 5.11 & 0.02 & 5.28 & 0.02 \\
\hline 2 & 1.48 & 0.03 & 5.06 & 0.02 & 5.36 & 0.01 \\
\hline \multicolumn{7}{|l|}{ Upper } \\
\hline 1 & 1.56 & 0.02 & 5.18 & 0.01 & 4.92 & 0.01 \\
\hline 2 & 1.80 & 0.01 & 5.18 & 0.01 & 4.91 & 0.01 \\
\hline
\end{tabular}

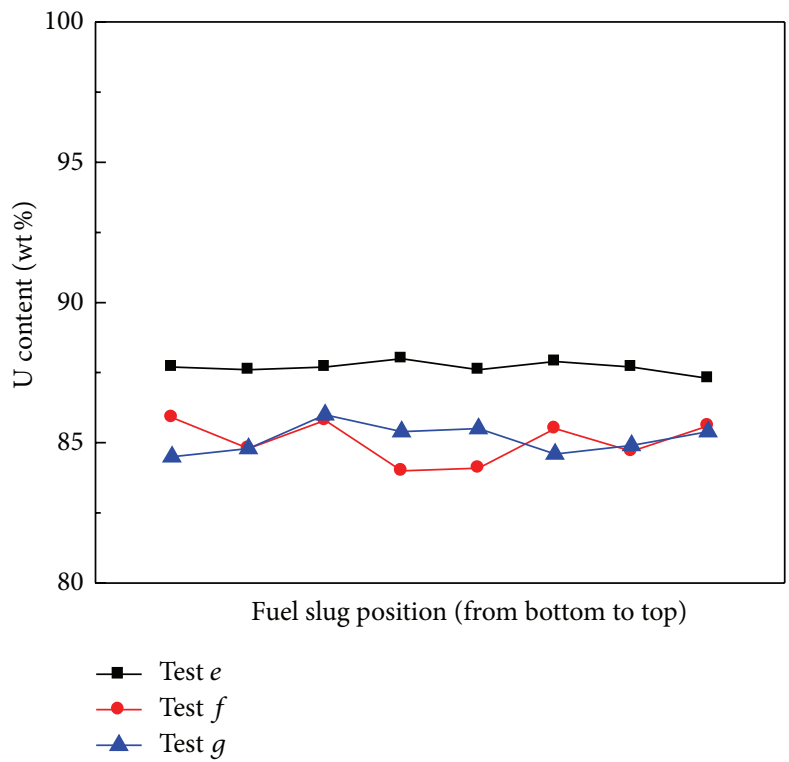

(a)

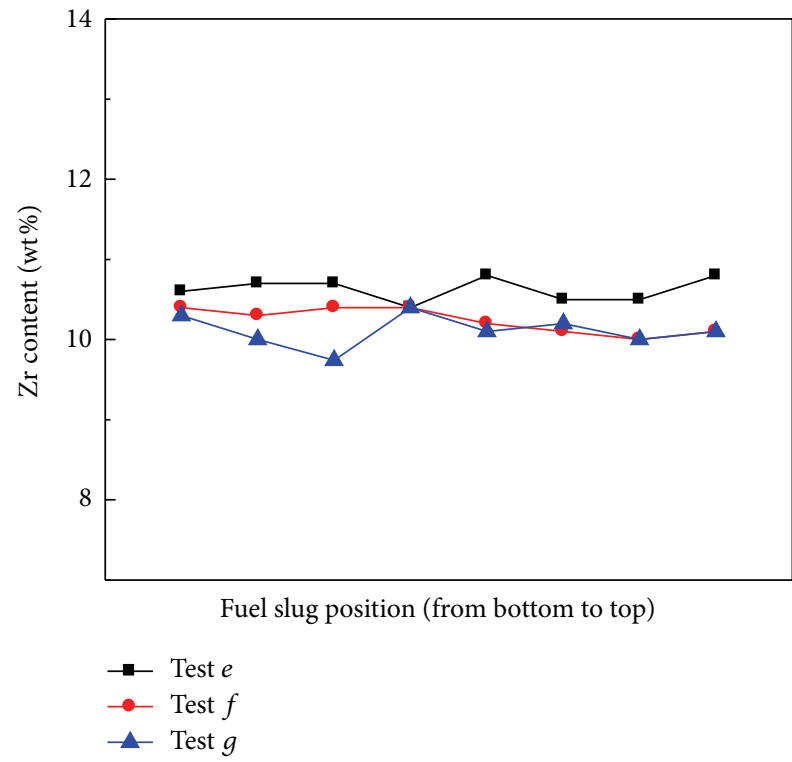

(b)

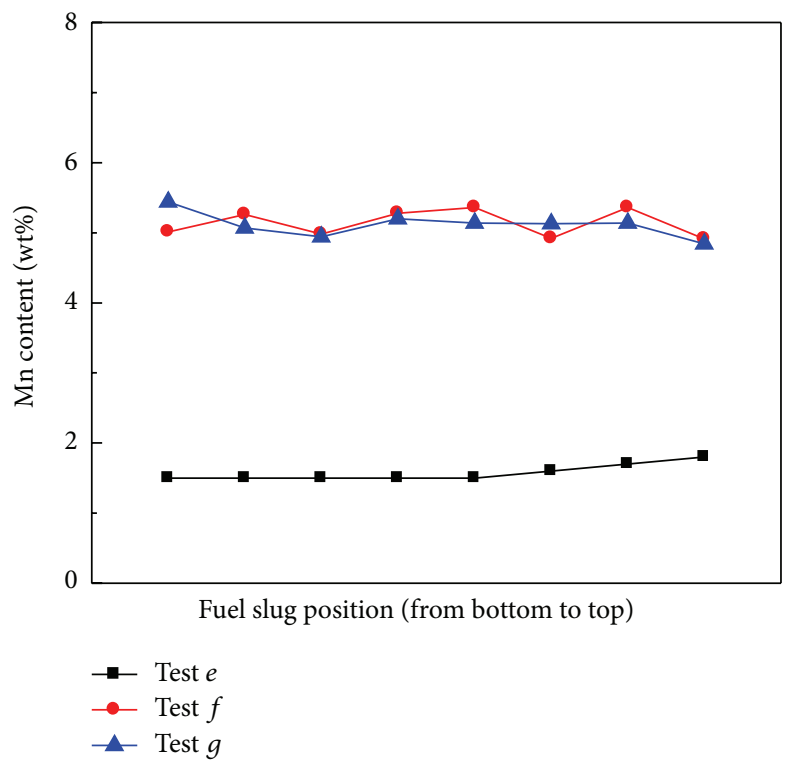

(c)

FIGURE 6: Variations of chemical composition according to the position of a U-Zr-Mn fuel slug fabricated under different injection casting conditions: (a) U, (b) Zr, and (c) Mn. 


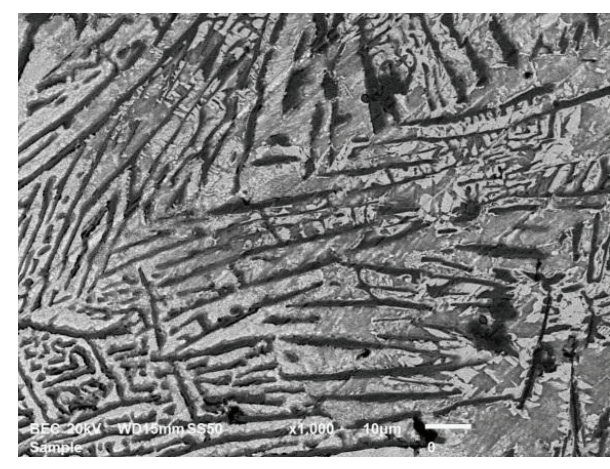

(a)

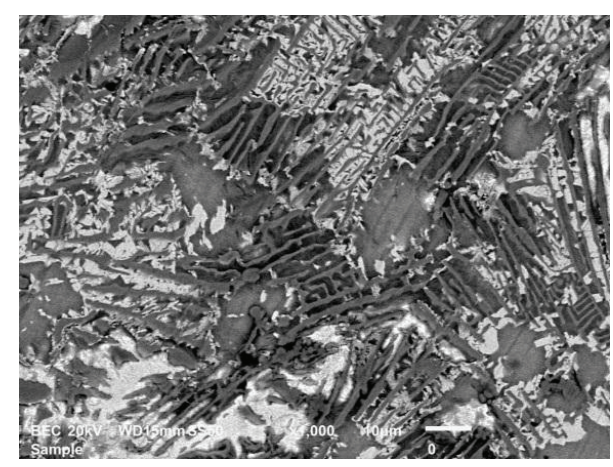

(b)

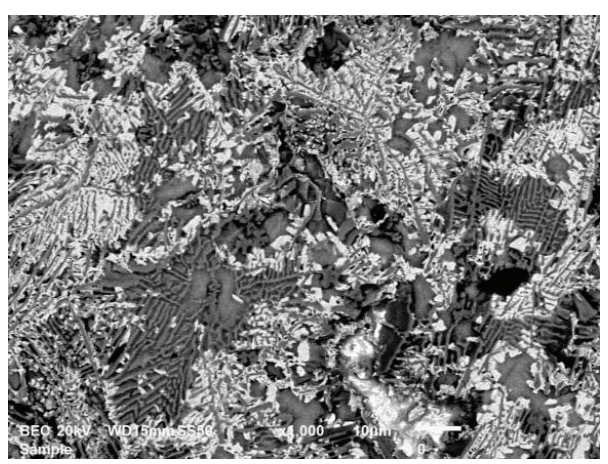

(c)

FIGURE 7: Scanning electron micrographs according to position of as-cast $\mathrm{U}-\mathrm{Zr}-\mathrm{Mn}$ fuel slug prepared in test $e$ : (a) lower region, (b) middle region, and (c) upper region.

suggested already by its increased density. As mentioned above, this is the result of Mn vaporization (Figure 6(c)).

The microstructures at different positions of the as-cast fuel slug were examined to determine the effect of cooling rate. Figure 7 shows scanning electron micrographs of the lower, middle, and upper portions of the U-10Zr-5Mn fuel slug prepared in test $e$. It can be observed that the interlamellar spacing is large at the lower portion and becomes smaller at the upper portion. The reduction in interlamellar spacing at the upper portion can be explained by the cooling conditions. Because the lower portion is continuously heated by the high-temperature melt during the casting process, it has a lower cooling rate compared to the middle and upper portions. Hence, the thermal undercooling is relatively high at the upper portion, which leads to a high rate of nucleation and a smaller interlamellar spacing. The chemical composition of the lamellar structure was elucidated using an electron microscope fitted with an energy-dispersive Xray analyzer, as shown in Figure 8. Figure 8(a) is a magnified image of the micrograph shown in Figure 7(a). The plate-like phase marked by "A" shows a higher content of $\mathrm{Zr}$ and $\mathrm{Mg}$ and lower content of $U$ (Figure 8(b)), and the block phase marked by "B" shows a higher U content and lower Zr content (Figure 8(c)).

Quantifying and reducing the amount of fuel lost during its preparation are crucial because large recycling and waste streams lower the productivity and economic efficiency of the production process. The material balances in the crucible and in the mold were quantified after casting the $\mathrm{U}-\mathrm{Zr}-\mathrm{Mn}$ slugs, as shown in Table 3. While a large amount of fuel is lost by casting under dynamic vacuum conditions, the fuel loss is within $0.1 \mathrm{wt} \%$ when casting under 400 or 600 Torr Ar. The fuel losses relative to the initial contents are $3.1 \%, 0.06 \%$, and $0.04 \%$ in tests $e, f$, and $g$, respectively. This result indicates that fuel loss decreases as the atmosphere pressure increases, becoming very small for pressures greater than 400 Torr.

\section{Conclusions}

As surrogates for the U-TRU-Zr slugs proposed to fuel SFRs, U-10Zr-5Mn slugs were injection cast under different conditions in a laboratory-scale furnace and their characteristics were evaluated. The effects of injection temperature, electromagnetic stirring, and immersion time were evaluated in preliminary tests conducted using $\mathrm{Cu}$ slugs. As-cast $\mathrm{U}-\mathrm{Zr}-\mathrm{Mn}$ slugs were generally sound, without cracks or thin sections. The shorter the as-cast $\mathrm{U}-\mathrm{Zr}-\mathrm{Mn}$ slugs, the higher the atmosphere pressure. Under dynamic vacuum conditions, approximately $68 \%$ of the original Mn content was lost by vaporization, and the resulting $\mathrm{U}-\mathrm{Zr}-\mathrm{Mn}$ fuel slug was denser than that prepared under Ar atmosphere. This result indicates that fuel slugs containing volatile minor actinides should not be injection cast under dynamic vacuum conditions. Increasing the atmosphere pressure is also shown here to reduce fuel loss. All the U-Zr-Mn slugs prepared in this study contained less than 2,000 ppm impurities (namely, 


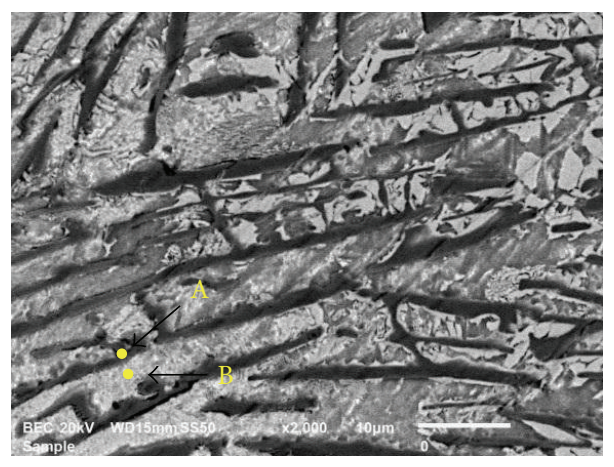

(a)

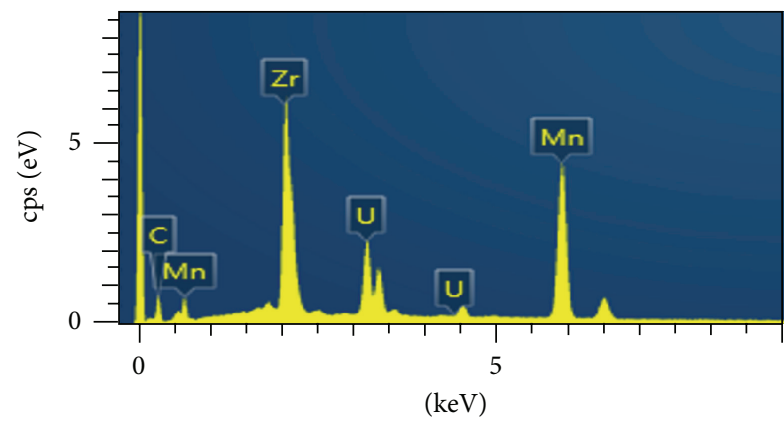

(b)

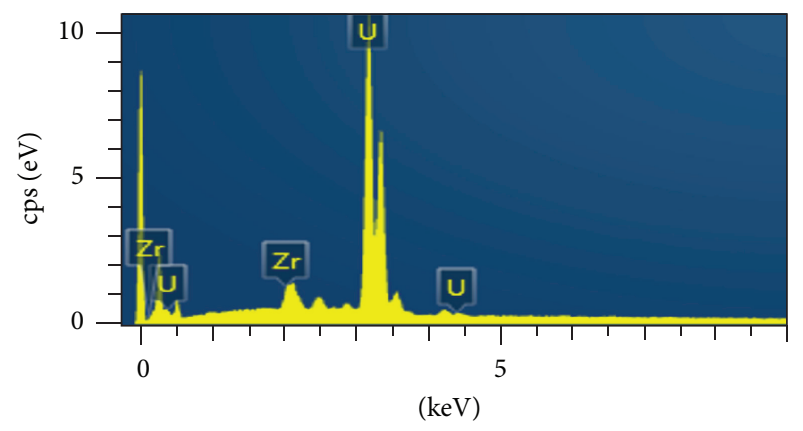

(c)

Figure 8: (a) Magnified image of the micrograph shown in Figure 7(a), and EDX spectra at (b) spot “A” and (c) spot "B" marked in (a).

TABLE 3: Material balance after injection casting of $\mathrm{U}-10 \mathrm{wt} \% \mathrm{Zr}-5 \mathrm{wt} \%$ RE fuel slugs.

\begin{tabular}{lccccccc}
\hline & \multirow{2}{*}{ Casting part } & \multicolumn{2}{c}{ Test $e$} & \multicolumn{2}{c}{ Test $f$} & \multicolumn{2}{c}{ Test $g$} \\
& & Mass (g) & Fraction (\%) & Mass (g) & Fraction (\%) & Mass (g) & Fraction (\%) \\
\hline Before casting & Crucible assembly & 607.2 & 100 & 428.1 & 100 & 420.19 & 100 \\
After casting & Crucible assembly & 497.1 & 81.86 & 362.3 & 84.62 & 365.0 & 86.90 \\
\multirow{2}{*}{ Fuel loss } & Mold assembly & 91.3 & 15.04 & 65.5 & 15.30 & 55.0 & 13.10 \\
\hline
\end{tabular}

oxygen, carbon, silicon, and nitrogen), satisfying the criteria defined for SFR fuels.

\section{Conflict of Interests}

The authors declare that there is no conflict of interests regarding the publication of this paper.

\section{Acknowledgment}

This study was supported by Nuclear Research \& Development Program of the National Research Foundation Grant funded by the Ministry of Education, Science and Technology in Korea (Grant no. 2013M2A8A2000676).

\section{References}

[1] C. E. Stevenson, The EBR-II Fuel Cycle Story, American Nuclear Society, La Grange Park, Ill, USA, 1987.
[2] L. C. Walters, B. R. Seidel, and J. H. Kittel, "Performance of metallic fuels and blankets in liquid-metal fast breeder reactors," Nuclear Technology, vol. 65, no. 2, pp. 179-231, 1984.

[3] L. C. Walters and G. L. Hofman, "Metallic fast reactor fuels: a comprehensive treatment," Materials Science and Technology A, vol. 10, pp. 1-43, 1994.

[4] G. L. Hofman, L. C. Walters, and T. H. Bauer, "Metallic fast reactor fuels," Progress in Nuclear Energy, vol. 31, no. 1-2, pp. 83110, 1997.

[5] D. C. Crawford, D. L. Porter, and S. L. Hayes, "Fuels for sodium-cooled fast reactors: US perspective," Journal of Nuclear Materials, vol. 371, no. 1-3, pp. 202-231, 2007.

[6] D. E. Burkes, R. S. Fielding, D. L. Porter, D. C. Crawford, and M. K. Meyer, "A US perspective on fast reactor fuel fabrication technology and experience part I: metal fuels and assembly design," Journal of Nuclear Materials, vol. 389, no. 3, pp. 458469, 2009.

[7] D. E. Burkes, R. S. Fielding, and D. L. Porter, "Metallic fast reactor fuel fabrication for the global nuclear energy partnership," Journal of Nuclear Materials, vol. 392, no. 2, pp. 158-163, 2009. 
[8] H. A. Kick and R. N. R. Mulford, "Vapor pressure of neptunium," The Journal of Chemical Physics, vol. 41, no. 5, pp. 14751478, 1964.

[9] S. C. Carniglia and B. B. Cunningham, "The vapor pressure of americium metal," Journal of the American Chemical Society, vol. 77, no. 6, p. 1502, 1955.

[10] R. J. Ackermann and E. G. Rauh, "The thermodynamics of vaporization of neptunium and plutonium," The Journal of Chemical Thermodynamics, vol. 7, no. 3, pp. 211-218, 1975.

[11] R. N. R. Mulford, "Thermodynamics," in Proceedings of the Symposium on Thermodynamics, vol. 1, p. 231, IAEA, Vienna, Austria, July 1965.

[12] A. Pattoret, J. Drowart, and S. Smoes, "Thermodynamics of nuclear materials," in Proceedings of a Symposium in Vienna, 1967, p. 613, IAEA, Vienna, Austria, 1968.

[13] J. W. Ward, W. Muller, and G. F. Kramer, "Transplutonium elements," in Proceedings of Fifth International Conference in Baden-Baden, 1975, European Institute for Transuranium Elements, Karlsruhe, Germany, 1975.

[14] O. Kubaschewski, Materials Thermochemistry, Pergamon Press, New York, NY, USA, 6th edition, 1993.

[15] P. L. Woolf, G. R. Zellars, E. Foerster, and J. P. Morris, Vapor Pressures of Liquid Manganese and Liquid Silver, US Department of the Interior, Bureau of Mines, 1960.

[16] T. B. Massalski, P. R. Subramanian, H. Okamoto, and L. Kacprzak, Binary Alloy Phase Diagrams, ASM International, 1990.

[17] R. S. Fielding and D. L. Porter, "Volatile species retention during metallic fuel casting," Journal of Nuclear Materials, vol. 441, no. 1-3, pp. 530-534, 2013.

[18] J. H. Kim, H. Song, H. T. Kim, K. H. Kim, C. B. Lee, and R. S. Fielding, "Development of a new casting method to fabricate U$\mathrm{Zr}$ alloy containing minor actinides," Journal of Radioanalytical and Nuclear Chemistry, vol. 299, no. 1, pp. 103-109, 2014. 

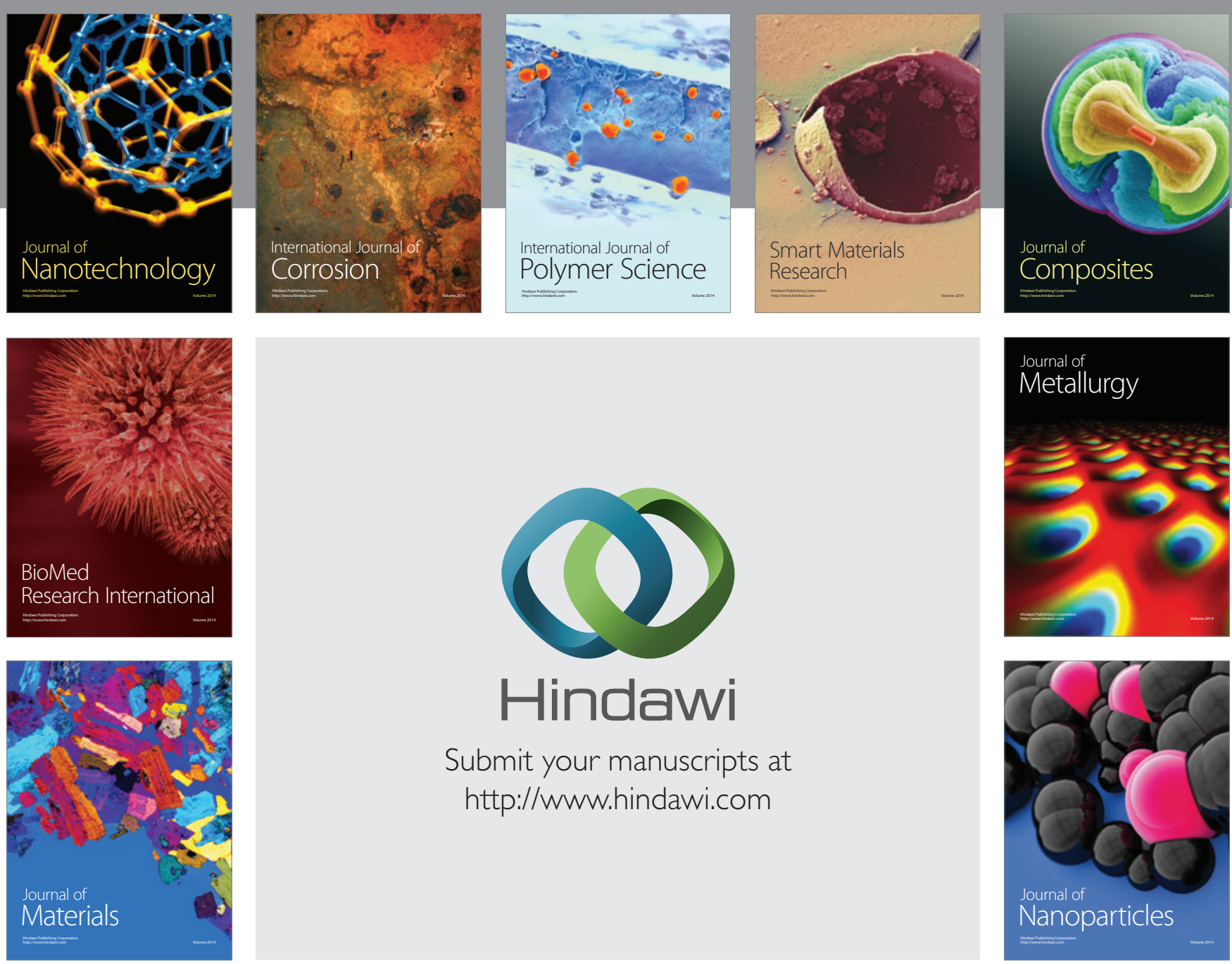

Submit your manuscripts at http://www.hindawi.com
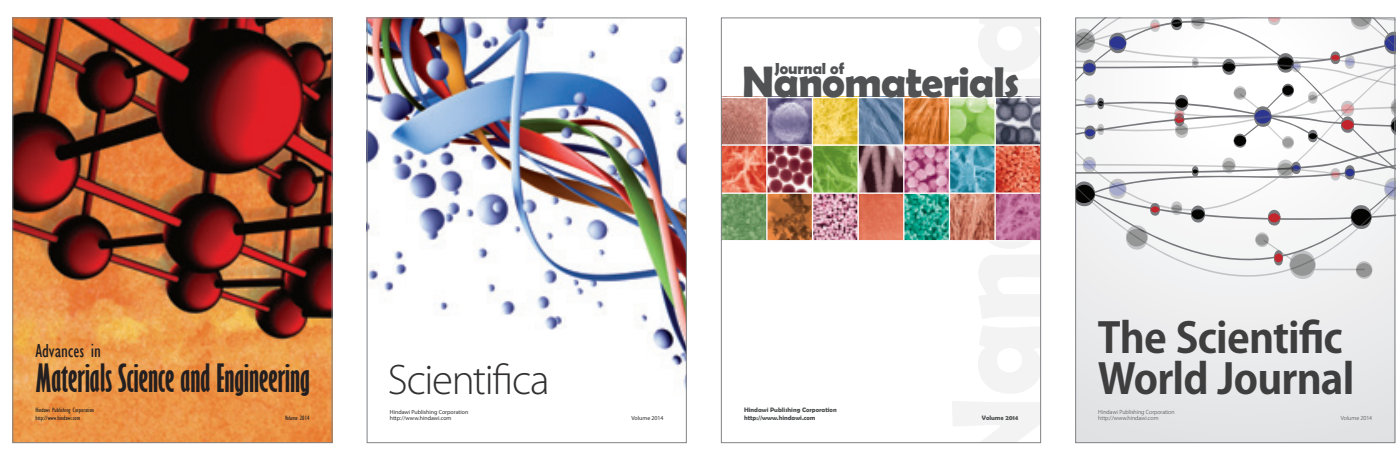

\section{The Scientific World Journal}
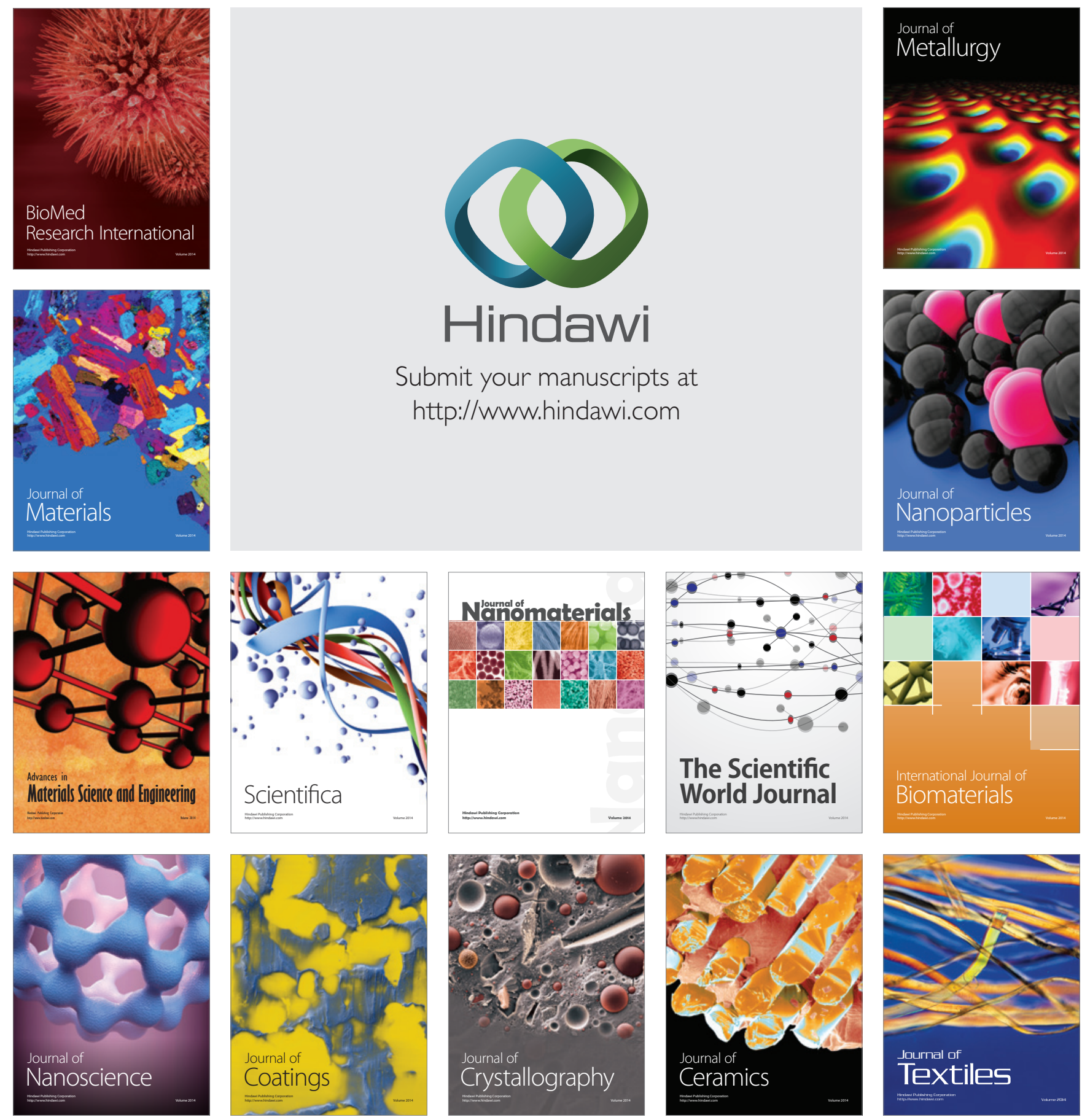